\title{
Recurrent Rectal Carcinoma
}

National Cancer Institute

\section{Source}

National Cancer Institute. Recurrent Rectal Carcinoma. NCI Thesaurus. Code C9238.

The reemergence of rectal carcinoma after a period of remission. 